\title{
Euthanasia: A Perspective
}

\author{
Dr. Roopali Gupta \\ Assistant Professor \\ Gokul Das Hindu Girls' College \\ Moradabad \\ Email: roopaliguptaofficial@gmail.com
}

\begin{abstract}
The moral permissibility of euthanasia is one of the most controversial questions confronting our society today. In this paper, I will attempt to weigh the pros and cons of legalizing euthanasia and physician-assisted suicide and discuss the various issues pertinent to the subject. I will discuss euthanasia from morality, bioethics, societal norms, legality, human rights, and the limitations of human autonomy, among others. Euthanasia, whether it is voluntary or involuntary, or whether we refer to it by a euphemism (death with dignity' or 'assisted suicide') is still homicide, and its legalization in several countries is bound to lead to undesirable consequences in the future. I am of the view that legalizing euthanasia would be a gross failure to those vulnerable people in our society who need our love and compassion rather than a death sentence.

Keywords: Euthanasia, Physician-Assisted Suicide, Palliative Care, Mercy Killing
\end{abstract}

\author{
Reference to this paper \\ should be made as \\ follows:

\section{Dr. Roopali Gupta} \\ Euthanasia: \\ A Perspective \\ Journal Global \\ Values, \\ Vol. XI, No.I, \\ Article No.5, \\ pp. $34-42$ \\ http://anubooks.com/ \\ ?page_id $=6195$ \\ https://doi.org/ \\ 10.31995/ \\ jgv.2020.v11i01.005
}




\section{Introduction}

Euthanasia, also known as mercy killing, is defined as a deliberate intervention undertaken with the express intention of ending a life to relieve intractable suffering. ${ }^{1}$ Literally meaning 'good death', euthanasia has become a widely debated topic of contention in the field of bioethics. It encompasses complex and diverse aspects like moral, ethical, legal, economic, medical, religious, and the issue of human rights and human autonomy, among others. This paper attempts to examine the pros and cons of euthanasia after taking into consideration all these aspects and the possible ramifications of legalizing euthanasia in the contemporary zeitgeist.

From a historical point of view, euthanasia has been a topic of controversy for thousands of years. It was practiced in ancient Greece and Rome, and supported by philosophers like Socrates, Plato, and Seneca the elder. However, Hippocrates, the father of modern medicine, rejected it outright. In the early modern period, Sir Thomas More recommended euthanasia in his book Utopia. Francis Bacon and Karl Marx have described euthanasia in terms of supporting someone as they died. In the nineteenth century, the first popular advocate of active euthanasia was a schoolmaster named Samuel Williams. In 1870 he wrote the first paper to deal with the concept of 'medicalized' euthanasia. ${ }^{2}$

In the $20^{\text {th }}$ century, the first attempt to legalize euthanasia was attempted in the United States, at the behest of wealthy heiress Anna S. Hall, who had watched her mother suffer due to cancer of the liver. The bill seeking to legalize euthanasia called for the administration of an anesthetic to bring about death, when recovery was impossible and pain unbearable. In 1920, two German professors Binding and Hoche published a book with the title The Release of the Destruction of Life Devoid of Value, Its Measure and Its Form. ${ }^{3}$ Hoche advocated euthanasia as a proper and legal medical procedure to kill the weak and vulnerable so as not to taint the human gene. Adolf Hitler admired Hoche's writing and popularised and propagandized the idea, leading to the holocaust and the involuntary euthanasia practiced during the Third Reich.

In the present century, the debate on euthanasia rages on, with several countries having opted to legalize euthanasia. The reason for this is clear - the tremendous advancement in medical knowledge and the corresponding increase in human life span has ensured that more people than ever are dying of old age and its concurrent deterioration in mental and physical capacity. John Keown in his book Euthanasia, Ethics and Public Policy writes "whether the law should permit voluntary euthanasia or physician-assisted suicide is one of the most vital questions facing all modern societies" ${ }^{4}$ 
Euthanasia is often sub-classified as voluntary, involuntary, and passive. When a patient has given informed consent to a lethal injection, the term 'voluntary euthanasia' is used, and when consent is unavailable it is called 'involuntary euthanasia'. Passive euthanasia is the withholding of treatment necessary for the continuation of life (also called slow euthanasia). It can be thought of as death by omission rather than by commission (as inactive euthanasia). Passive euthanasia is not considered to be a crime. Even the use of pain alleviating substances such as morphine and chloroform - although they may have the potential to alter consciousness, change the state of mind, and even cause death - is not a crime because the motive is not to kill but to alleviate pain. Active euthanasia, on the other hand, is considered to be a homicide.

Another term that is used synonymously with Euthanasia is PAS - PhysicianAssisted Suicide, but both terms are different and have different legal implications. Michael Manning, M.D. defines physician-assisted suicide as follows: "A physician providing medications or other means to a patient with the understanding that the patient intends to use them to commit suicide". ${ }^{5}$

Autonomy - the right to self-determination - is a progressively recognized value of modern societies and it is this value that is at the basis of the euthanasia debate. The pro-euthanasia and assisted suicide lobby to argue that individual autonomy is paramount to all other concerns, that one has absolute right over one's body, and that death is a private matter. The state therefore ought not to have any say in the manner or time of the death of an individual. It would appear that refusing a suffering and terminally ill patient the right to die is an infringement on that person's liberty to die with dignity. This is the kind of thought that has led to the popularity of 'suicide tourism', where the people weary of life buy a one-way ticket to a country in which euthanasia is legal. If one owns one's own life, and no one else has the right to interfere with what one decides for oneself in that regard (as pro-euthanasia advocates claim), then respect for the person's autonomy as a sufficient justification means that the person need not be suffering to access euthanasia. This approach is manifested in the proposal in the Netherlands that euthanasia should be available to those "over 70 and tired of life". ${ }^{6}$

Mercy has also become one of the main arguments in support of the euthanasia movement. Healthcare has its limitations and patients are afraid of being trapped in life-support machines as they approach death. They can take away a person's selfconcept, character, sense of self-worth and self esteem. ${ }^{7}$

Many healthcare professionals and bio-ethicists also argue in favor of the 'futile care theory' - which measures the value of human life according to the financial cost of keeping the individual alive ${ }^{8}$ For instance in the case of a person who is in a 
persistent vegetable State (PVS) - a state of no cognition and no self-awareness the questions naturally arise that should he or she be kept alive pointlessly and at great financial burden? Should not his or her organs be harvested and then he or she euthanized? Also, there can be a doubt that with the boom in lifestyle diseases such as diabetes mellitus and hypertension, our healthcare systems are bound to come under tremendous pressure in the coming decades. There may not be enough healthcare professionals in the future to provide long term palliative care. In the last decades, the sociological background of many countries has also changed dramatically. The nuclear family is smaller, so informal caregiving at home could seriously compromise the lives of the caregivers and palliative care at a hospice is often very expensive.

Further, in the absence of a law legalizing euthanasia a patient may even resort to VSED -voluntarily stopping eating and drinking, or decide to exercise his or her right to refuse life-saving treatment. Pain medication may have to be increased to a point where the patient remains permanently sedated. In these cases, death becomes inevitable and comes quickly.

All these valid points in support of legalizing euthanasia lead to the following questions - can euthanasia and assisted suicide to be considered morally permissible? When suffering is relentless should euthanasia be available as an option? Is death truly a personal matter? Does it matter how we choose to die, behind closed doors, if our choice does not affect anyone else? Should the state be responsible for providing quality palliative care? Can our already overburdened medical system handle the increased cost of such measures? Is it more humane to let people die than to force them to live out their natural life span while suffering excruciating pain? And finally, can homicide ever be thought of as therapeutic?

The answers to these questions are rather complex because apart from implying a fundamental shift in values, legalizing euthanasia poses a few key concerns. Firstly, the thought of years, even months, of an uphill struggle with pain is inarguably a daunting thought and were euthanasia to become widely legalized It would provide a very enticing alternative to any person who has been diagnosed with a terminal disease and is afraid to suffer the inevitable pain and deterioration of the life force. Secondly, the medical profession would in all probability become more relaxed in searching for newer cures to terminal diseases as euthanasia would provide an easy alternative. Thirdly, interminable pain might not be the only reason somebody seeks euthanasia. Many elderly people who have lost the ability to function independently would rather die than to suffer the inevitable loss of dignity or feel that they will be a burden to caregivers. During 14 years (1998-2012), the three most frequently 
mentioned end-of-life concerns were loss of autonomy (91.4\%), decreasing ability to par-ticipate in activities that made life enjoyable (88.9\%), and loss of dignity $(80.9 \%){ }^{9}$

Looking at euthanasia for medical ethics, international guidelines following the Hippocratic Oath and the World Medical Association Declaration of Geneva still consider euthanasia and physician-assisted suicide as a morally forbidden practice because it is absolutely incompatible with the role of the physician as 'healer'. The practice of medicine is necessarily constrained by moral absolutes, and in euthanasia, the very relationship between the doctor and the patient is compromised. Physicianphilosopher Edmund Pellegrino states it well: "Physicians must never kill. Nothing is more fundamental or uncompromising". ${ }^{10}$ Apart from the ethical aspect, in its 1994 report The House of Lords Select Committee on Medical Ethics concluded: "It was virtually impossible to ensure that all acts of euthanasia were truly voluntary and that any liberalization of the law in the United Kingdom could not be abused. We were also concerned that vulnerable people - the elderly, lonely, sick or distressed - would feel pressure, whether real or imagined, to request early death." 11

In the Indian context also suicide and abetment to suicide are both criminal offenses, though both are distinct from each other. The Supreme Court holds that the person attempting suicide needs help and compassion rather than punishment because it is only under depression that a person thinks of committing suicide. In classical teaching as well the attempt to suicide is a psychiatric emergency and it is considered as a desperate call for help or assistance. Hence, attempted suicide is considered as a sign of mental illness. ${ }^{12}$ Further, the Supreme Court holds that the Right to life under Article 21 of the Constitution does not include the Right to die ${ }^{13}$ although the Right to refuse medical treatment is well recognized in law, including medical treatment that sustains or prolongs life. For example, a patient suffering from blood cancer can refuse treatment or deny feeds through a nasogastric tube. Recognition of the Right to refuse treatment gives a way for passive euthanasia which is quite prevalent in India - with the privatization and commercialization of health care more and more people are finding it impossible to opt for assisted palliative care and those few who can afford it are unwilling to do so, either at the express wishes of the patient or sometimes because the caretakers believe that the agony and suffering of the patient will be unnecessarily prolonged.

Another very compelling argument against euthanasia is that with the advancement in modern medicine and healthcare the quality of palliative healthcare

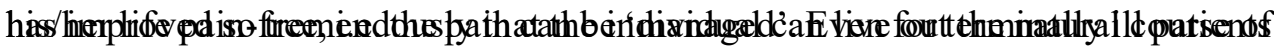


suffering from cancer, there is a range of analgesics available that may cause the patient to be in deep sedation most of the time but will relieve pain. Sedation can include giving morphine or narcotic analgesics to a terminal patient in pain. It is meant to give patients comfort, which is why it is called Palliative Sedation. It is used when it is the only reasonable way to control pain and suf-fering and is given with that intention. It is not euthanasia. 'Terminal Sedation,' which is another option while dealing with unbearable pain, refers to a situation in which the patient's death is not imminent and the patient is sedated with the primary intention of precipitating their death. ${ }^{14}$ Although euthanasia may appear to be a very viable option, especially when a loved one is undergoing intense suffering, taking the final decision to administer euthanasia can be very taxing for everyone involved in the decision making process. In many such instances, passive euthanasia - the discontinuation of life-sustaining treatment, or Terminal sedation is the option many caregivers prefer. Palliative care is very important in this regard because it provides a chance for a relatively painfree existence, and most importantly it neither hastens nor postpones death, thereby absolving the caregivers of the moral responsibility of the tough decision of considering euthanasia.

Euthanasia is a cause for concern primarily because it involves one person actively facilitating the death of another. Those who base their arguments on human autonomy forget that there cannot be a 'Right to Die' because no person has the obligation to assist in suicide. We must not forget that the 'Right to die' is not a fundamental right. It is different from 'Right to be allowed to die', where the sufferer can refuse life-saving treatment, or resort to VSED (voluntarily stopping eating and drinking) to hasten death. The latter is a passive approach, while the former requires a perpetrator. Those who support euthanasia based on autonomy need to understand that neither Euthanasia nor physician-assisted suicide can be considered to be autonomous decisions because neither is carried out in isolation, and family members, friends, healthcare staff, and society at large - all are affected by this personal choice.

The most difficult aspect of the life of a terminally ill person is that in most cases, the mind is sound. The ability to be cognizant of everything that is happening around them, the awareness of the inconvenience to the caregivers, the indignity of needing assistance with all bodily functions, - all these are keenly felt. It could easily lead to 'patient's guilt'. This guilt could be regarding the financial implications of treatment, the physical burden, or the emotional burden of having to see a loved one suffer due to one's own suffering. This will inevitably put pressure on the terminally ill to opt for euthanasia and 'Right to die' could easily become 'Duty to Die' as 
patients feel they have outlived their utility in this world and must now opt for death so as not to cause inconvenience to those they are leaving behind. It could soon turn into a very ugly situation where the elderly, the disabled, the poor, people with stigmatized diseases might come under undue pressure to end their lives by callous physicians and family members incapable of caring for them. People who have no one to care for them might come to look at euthanasia as the only option available to them. Depressed people, who are already treading a fine line where the will to live is concerned, would be especially vulnerable. In cases where legacy or family inheritance is a stake, the situation would again become murky.

People who support euthanasia because it is compassionate to end the suffering of others must surely see that it is surely more compassionate to treat terminally ill people with love and compassion and assure them that their lives have value. Just because a person has become physically incapacitated or is in a vegetative state does not mean that his or her life is any less valuable. The thought of being in pain and dependent on others may make the terminally ill patients express the wish to be put to death, but even terminally ill patients do not truly wish to die. It is easy to imagine, when one is young and physically capable, that one could never be able to suffer the indignity of being dependent on others for everything, but the reality is that death is such a final act that one becomes willing to compromise with many previously unimaginable situations and conditions. If terminally ill people are offered adequate support and love and proper palliative care, they can undoubtedly live out their last days on earth in peace.

Also, Euthanasia will only lead to the value judgment of a patient's life and if the quality of life is seen as a criterion, then it will be easy to justify most cases of euthanasia. What we all need to accept as a society is that disability is a natural corollary to growing old. One cannot remain youthful and physically fit forever. With aging, the body starts to gradually die and the end especially is accompanied by several end-of-life processes that are not to be denied but are nothing to be afraid of. However, our society which places a very high value on independence and selfreliance, finds this final stage of life demeaning. We need to assure the terminally ill that they are not a burden and that nothing is demeaning about being dependent on others. Not all of us will die of old age and if we are lucky enough to do so we should embrace old age wholeheartedly and accept help from others without feeling guilt. It is the circle of life.

Finally, no euphemisms - assisted dying, medically assisted suicide, death with dignity - can change the fact that euthanasia is technically suicide/homicide, 
and while it is true that in a few carefully vetted cases euthanasia would indeed be the humane choice, it could well become a 'slippery slope', and since involuntary euthanasia would be tantamount to murder, it would hardly be in the best interests of the population at large to legalize it. The law exists to protect the weak, not to make them more vulnerable to malpractices.

There can be no doubt that the legalization of euthanasia would be a failure to society. Once we cross the line that it is wrong to intentionally kill another human being, even if they themselves request it, there is no logical stopping point. We have obligations to protect the weak, and euthanasia only facilitates their early demise. We are not products to be checked out of the supermarket of life when we are past our expiry date. Resorting to euthanizing the old and the weak would make us a cold, clinical society in which we are of value only so far as all our faculties are intact, and not one minute longer. This would become akin to Aldous Huxley's Brave New World, in which life and death are simply clinical facts, devoid of all emotional and social connotations. But we are not robots. We are human, and what makes us uniquely human is our sense of empathy. Were we to lose this empathy and start to think of the aged and the diseased as disposable, we would be committing an unforgivable crime towards humanity.

\section{References}

1. Rodway, A., Collins, K., Gilhooly, M., Murray, K., Twycross, R., Helme, T., et al. (1994). Euthanasia.309, (52nd ed., Vol. 309). N/A

2. Emanuel E J. The history of euthanasia debates in the United States and Britain. Ann Intern Med. 1994; 121:793-802. [Pub Med] [Reference list]

3. Binding, Karl, and Hoche, Alfred. The Release of the Destruction of Life Devoid of Value, Its Measure, and Its Form. 1920. Published in Germany by Felix Meiner in Leipzig, comments by Robert L. Sassone, 1975, Santa Anna, California, (abridged - 112 pages).

4. Keown, J. Euthanasia, ethics, and public policy. An argument against legalization. Cambridge: Cambridge University Press, (2002)

5. Manning, Michael, Euthanasia and Physician-Assisted Suicide, Published: New York: Paulist Press, [1998], 4.

6. Smith, WJ. Euthanasia Created Dutch Culture of Death: Elderly "Tired of Life" Next Category for Termination. Web. <http://www.firstthings.com/ blogs/firstthoughts/2010/02/euthanasia-created-dutch-culture-of-deathelderly-tired-of-life-next-category-for-termination/>

7. Cohen-Almagor, Raphael. The Right to Die with Dignity: An Argument in 
Euthanasia: A Perspective

Dr. Roopali Gupta

Ethics and Law, Health Law \& Policy (2008):2-8.

8. The Life Resources Charitable Trust, A General History of Euthanasia. n.d. Web.

$<$ http://www.life.org.nz/euthanasia/abouteuthanasia/history-euthanasia1/ $>$

9. Oregon Death with Dignity Act Annual Reports Web. $<\underline{\text { http: } / /}$ public.health.oregon.gov/ProviderPartnerResources/EvaluationResearch/ DeathwithDignityAct /Pages/ar-index.aspx $>$

10. Pellegrino, ED. Some things ought never to be done: moral absolutes in clinical ethics. Theor Med Bioeth. 20026(6):469-486.

11. Web. $<$ https://publications.parliament.uk/pa/ld200405/ldselect/ldasdy/86/ 5020324.htm>

12. Lonnqvist, J. The Oxford textbook of suicidology and suicide prevention. Oxford: Oxford University Press; 2009. Major psychiatric disorders in suicide and suicide attempters; pp. 275-86.

13. Gian Kaur vs. the State of Punjab, 1996(2) SCC 648 [Google Scholar]

14. Boudreau J Donald, Somerville, Margaret A. Euthanasia and assisted suicide: a physician's and ethicist's perspectives. Medicolegal and Bioethics. $17^{\text {th }}$ July 2014. Dove Press. Web. <https://www.dovepress.com/ 